\title{
Imigração em São Paulo: perfis segundo pobreza e ocupação no século XXI*
}

\author{
Pier Francesco De Maria ${ }^{\dagger}$ \\ Rosana Baeninger $*$
}

\section{RESUMO}

O presente artigo se propõe a fazer uma desagregação dos fluxos migratórios, tanto nacional como internacional, para o estado de São Paulo, com vistas a analisar as características socioeconômicas, demográficas e ocupacionais destes migrantes na primeira década do século XXI. O trabalho parte da hipótese de homogeneidade no perfil do imigrante, independente de este ir morar na metrópole (Região Metropolitana de São Paulo - RMSP), ou no interior. Este resultado seria reflexo de um processo de metropolização do interior, o qual tem ocorrido no estado de São Paulo ao longo das últimas décadas. O trabalho objetiva, assim, verificar a existência de diferenciais entre o interior e a metrópole, para discutir a validade da distinção entre estas áreas. Os resultados apresentados mostram que há algumas diferenças entre o interior e a RMSP, sobretudo em termos de perfil ocupacional e de composição dos fluxos imigratórios. Entretanto, não foram constatadas diferenças tão gritantes quanto ao perfil da migração. O que mantém em pé a necessidade de se separar interior de metrópole é a composição dos fluxos migratórios stricto sensu, significativamente distintos no século XXI. Constatou-se, enfim, que o interior urbano paulista necessita de algum tipo de desagregação, pois é possível que os resultados parecidos entre a RMSP e o interior urbano sejam fruto do efeito de composição deste interior - no qual convivem regiões metropolitanas, como a de Campinas e a da Baixada Santista, e áreas ainda de expansão urbana.

Palavras-chave: Migrações; Pobreza; Inserção ocupacional; São Paulo

\footnotetext{
* Trabalho apresentado no IX Encontro Nacional sobre Migrações, Campinas/SP, de 14 a 16 de outubro de 2015. Este trabalho é produto do projeto temático "Observatório das Migrações em São Paulo" (processo $\mathrm{n}^{\circ}$ 2014/04850-1) - FAPESP, NEPO/UNICAMP.

$\dagger$ Mestrando em Demografia pela UNICAMP, bolsista CAPES. Email: pier@ nepo.unicamp.br.

* Professora associada do Departamento de Demografia da UNICAMP. Email: baeninger@ nepo.unicamp.br.
} 


\title{
Imigração em São Paulo: perfis segundo pobreza e ocupação no século XXI
}

\author{
Pier Francesco De Maria
}

Rosana Baeninger

\section{INTRODUÇÃO}

A migração em direção a São Paulo pode ser considerada como heterogênea sob diversos pontos de vista, muito por causa do grau de desenvolvimento do estado e das oportunidades (de estudo, emprego e vida) oferecidas no Sudeste. Embora os fluxos migratórios não sejam exclusividade do estado paulista, boa parte das idas e vindas da população brasileira passa pela região, a qual serve tanto de receptora dos imigrantes (os quais podem tanto retornar à sua origem como permanecer no destino), assim como de ponte para outros destinos - muitas vezes para além das fronteiras nacionais.

Deste modo, a imigração para São Paulo não é homogênea: migrantes de diversos estratos e perfis socioeconômicos, motivações distintas e trajetórias migratórias diversas se confundem nestes fluxos constantes. Ademais, embora tais fluxos sejam direcionados ao estado em si, tampouco são homogêneos em termos de destino: há quem vá para o interior e quem se dirija à metrópole, assim como os que saem de São Paulo são oriundos da capital (e seu entorno metropolitano) ou do grande interior paulista. Ambos os espaços (interior e metrópole) também têm fluxos heterogêneos, cabendo analisar qual o perfil da população migrante com base em: sua origem e seu destino; sua inserção (em termos de ocupação); seu perfil socioeconômico; e suas motivações.

Perante este quadro heterogêneo e complexo das imigrações em São Paulo, o presente artigo se propõe a fazer uma desagregação destes fluxos, com vistas a analisar as características socioeconômicas e ocupacionais dos migrantes. Para tal, a proposta é dividir os imigrantes segundo seu destino, para depois estudar a composição destes por estrato socioeconômico (pautado em elementos monetários) e inserção no mercado de trabalho (verificando em que setores da economia paulista os imigrantes se inserem). O presente trabalho busca assim analisar o papel de São Paulo no contexto migratório nacional nos anos 2000, bem como aprofundar aspectos da dinâmica intra-estadual.

O trabalho se pauta sobre a hipótese de um maior grau de homogeneidade no perfil do imigrante, reflexo de um processo de metropolização do interior. Com isto, o artigo objetiva analisar, sobretudo em termos socioeconômicos, os perfis da população que imigra para São Paulo. Correlatamente, o trabalho se propõe a: 1) verificar a existência de diferenciais 
significativos entre o interior e a metrópole; e 2) discutir a validade da distinção entre metrópole (entendida aqui como a Região Metropolitana de São Paulo) e interior (que, assim, compreende o restante do Estado).

O presente trabalho se encontra dividido em 5 seções, incluindo esta breve introdução. Na seção 2, é feita uma recuperação a respeito dos aspectos teóricos da migração no Brasil nas últimas décadas. Na seção 3, apresentam-se os materiais e os métodos utilizados para o presente estudo, de modo que, na seção 4, os mais relevantes resultados sejam expostos. Finalmente, na seção 5 deste artigo, são tecidos breves comentários conclusivos, discutindo a validade das hipóteses e os resultados obtidos.

\section{ASPECTOS TEÓRICOS DA MIGRAÇÃO NAS ÚLTIMAS DÉCADAS ${ }^{1}$}

As tendências gerais dos deslocamentos populacionais no Brasil, ocorridos desde os anos 1930 até a década de 1970, estiveram ancoradas na enorme transferência de população do meio rural para o urbano, nas migrações com destino às fronteiras agrícolas, no fenômeno da metropolização e na acentuada concentração urbana.

Na vertente da migração rural-urbana, Singer (1973) contextualizou esses movimentos migratórios no bojo do processo de industrialização em curso, cujos deslocamentos populacionais - com origem no rural e destino no urbano - representavam a força de trabalho necessária à etapa de acumulação capitalista. As áreas rurais estagnadas ou em processo de transformação contribuíam para "fatores de estagnação" ou "fatores de mudanças", impulsionadores de fluxos migratórios nos locais de origem, onde as "causas" e os "motivos" da migração eram resultantes das transformações econômicas globais da sociedade. Os excedentes populacionais do rural constituíam transferências populacionais para as cidades, com a incorporação desses contingentes no mercado de trabalho industrial em expansão.

Embora os movimentos migratórios rural-urbano fossem a principal força redistributiva da população - principalmente nos anos 1950 e 1960 -, o panorama dos movimentos migratórios no Brasil foi se ampliando a partir de então, até mesmo pela nova etapa de desenvolvimento econômico que o País viria a assistir ${ }^{2}$. Segundo Martine e Camargo (1984), o cenário da distribuição espacial da população brasileira, a partir dos anos 60, foi movido por forças centrífugas, com a expansão populacional rumo às áreas de fronteiras (migrações inter-regionais), e por forças centrípetas, com a migração rural-urbana em direção às grandes cidades do Sudeste, particularmente para a Região Metropolitana de São Paulo.

\footnotetext{
${ }^{1}$ Estas análises baseiam-se em Baeninger (2012).

${ }^{2}$ Veja-se, dentre outros, Cano (1988), Pacheco e Patarra (1997), Martine (1987).
} 
Já nos anos 1970, no bojo desta bipolaridade, faziam-se notar as forças de reforço à concentração (forças centrípetas), com a emigração das áreas de fronteiras agrícolas em direção às cidades maiores (MARTINE, 1987). Nesse contexto, a urbanização nacional operava em moldes cada vez mais concentradores, levando ao estabelecimento de um processo de distribuição da população que tendia a privilegiar os grandes centros urbanos do Sudeste. A partir dos anos 1980, essas forças se redefinem no entendimento das direções e sentidos das migrações internas.

As forças centrífugas, resultantes da atração exercida pelas fronteiras agrícolas, já haviam acentuado sua perda de importância nos anos $1970^{3}$, muito embora seus desdobramentos tenham ainda se refletido, nos anos 1980 e início dos anos 1990, nos movimentos migratórios. Já as forças centrípetas, em especial a exercida pela metrópole de São Paulo, arrefeceram após os anos 1980, porém não desapareceram ${ }^{4}$. Compondo um movimento mais amplo de distribuição populacional, a Região Metropolitana de São Paulo ao mesmo tempo em que ainda se mantém como o maior centro de recepção migratória passou também a se destacar pela importância de seu volume emigratório em nível nacional, emprestando recentes características ao processo de distribuição espacial da população e redefinindo alguns aspectos da migração interna.

As migrações internas assumem, nesse contexto, maior complexidade, particularmente pelo predomínio das migrações entre áreas urbanas; ou seja, movimentos migratórios constitutivos e elemento fundamental na configuração de novas espacialidades. $O$ entendimento do processo de reorganização da população no espaço desloca-se, portanto, do eixo de análise via migração rural-urbana, força motriz das análises centrípetas.

As migrações internas no Brasil, nas últimas décadas, foram marcadas por expressivas alterações em sua dinâmica, as quais se refletem nas novas especificidades e tendências do processo de distribuição espacial da população. Ao lado dos tradicionais fluxos migratórios, passam também a sobressair outras direções - movimentos de curta distância, movimentos de retorno e movimentos intra-regionais - e dimensões da migração, em particular a espacial, como elemento explicativo e determinante do fenômeno migratório.

As tendências recentes dos movimentos migratórios no Brasil suscitaram análises interpretativas enriquecedoras do debate atual. As transformações ocorridas no fenômeno migratório poderiam estar apontando: a configuração de um novo padrão migratório brasileiro (BRITO, 1997); o resultado das transformações ocorridas na sociedade e em sua dinâmica

\footnotetext{
${ }^{3}$ Em Martine (1987), encontra-se a evolução e declínio das áreas de fronteira no Brasil.

${ }^{4}$ Veja-se Baeninger (1999).
} 
econômica no mesmo período (PACHECO e PATARRA, 1997); variações de um mesmo processo historicamente referenciado no tempo e no espaço (CUNHA, 1999); a desconcentração da população vis-à-vis a desconcentração econômica (MATOS, 1995); a expansão dos espaços da migração (BAENINGER, 1999).

Mesmo com diferentes maneiras de interpretar o fenômeno, essas análises indicam, de modo geral, a partir dos anos 1980, as evidências e as características apontadas anteriormente: inflexão no ritmo de crescimento metropolitano; aumento nas migrações de curta distância; importância da migração de retorno; esgotamento da migração para as fronteiras agrícolas; e diminuição no ímpeto das migrações inter-regionais ${ }^{5}$. Os anos 1990 foram ainda mais desafiadores em termos de interpretações teóricas, particularmente em relação às análises pautadas na interiorização da indústria, uma vez que esse processo vem perdendo fôlego desde meados dos 1980.

Se, de um lado, os anos 1980 e 1990 assistiram à intensificação e à consolidação de tendências já observadas nos anos 1970, deve-se, contudo, considerar que, a partir de então, esses fenômenos estiveram contextualizados em tempos, momentos e espaços inseridos em outra sociedade: a sociedade de risco (BECK, 1992) ou a alta modernidade (GIDDENS, 1991). No século XXI, a compreensão dos fenômenos urbanos, em especial as novas formas de mobilidade espacial da população, passa por dimensões que, como reflexos de reestruturações na economia, compõem um novo mosaico das interações sociais.

A articulação de processos locais no âmbito regional e global promove "mecanismos de desencaixe" da sociedade (GIDDENS, 1991), com reflexos nos processos de urbanização e de redistribuição espacial da população nos variados contextos regionais. As novas territorialidades, por sua vez, aceleram seu processo de emergência na sociedade contemporânea, onde os riscos são compartilhados (OJIMA, 2003).

Nesse novo cenário, as novas territorialidades, abrangendo municípios diferenciados, estão imersas em um conjunto de "sistemas peritos" da sociedade (GIDDENS, 1991) - dentre os quais se destaca a facilidade de transportes -, contribuindo para a formação, a institucionalização e os desafios da gestão desses espaços, tanto em termos de migrações e de deslocamentos populacionais quanto de políticas sociais. $O$ aumento da migração intrametropolitana e intra-regional é também resposta aos espaços compartilhados da sociedade de risco e indica a necessidade de arranjos institucionais que contemplem essas novas territorialidades. O aprofundamento dessas interpretações, juntamente com o perfil dos

\footnotetext{
${ }^{5}$ Veja-se, a respeito: Martine e Camargo (1984), Martine (1987), Brito (1997), Cunha (1999), Pacheco e Patarra (1997) e Baeninger (1999).
} 
migrantes e sua inserção ocupacional, os fluxos migratórios e as condições de vida poderão contribuir para o entendimento do fenômeno migratório em São Paulo, bem como para a compreensão da relação migração e urbanização nos espaços metropolitanos e interioranos.

\section{MATERIAIS E MÉTODOS}

Neste trabalho, são utilizados os dados do Censo Demográfico de 2010, os quais permitem analisar e inferir resultados para a migração em áreas menores do que a UF (Unidade da Federação), diferentemente da PNAD (Pesquisa Nacional por Amostra de Domicílios). A partir das informações coletadas no questionário da amostra, é possível avaliar as seguintes características da migração interna:

- Tempo de moradia sem interrupção na UF e no município;

- Último local de residência (quesito "última etapa");

- Local de residência 5 anos atrás (quesito "data fixa").

Com estas informações, é possível separar os migrantes segundo sua localização no destino. A localização, para fins deste estudo, é definida conforme se apresenta na figura abaixo.

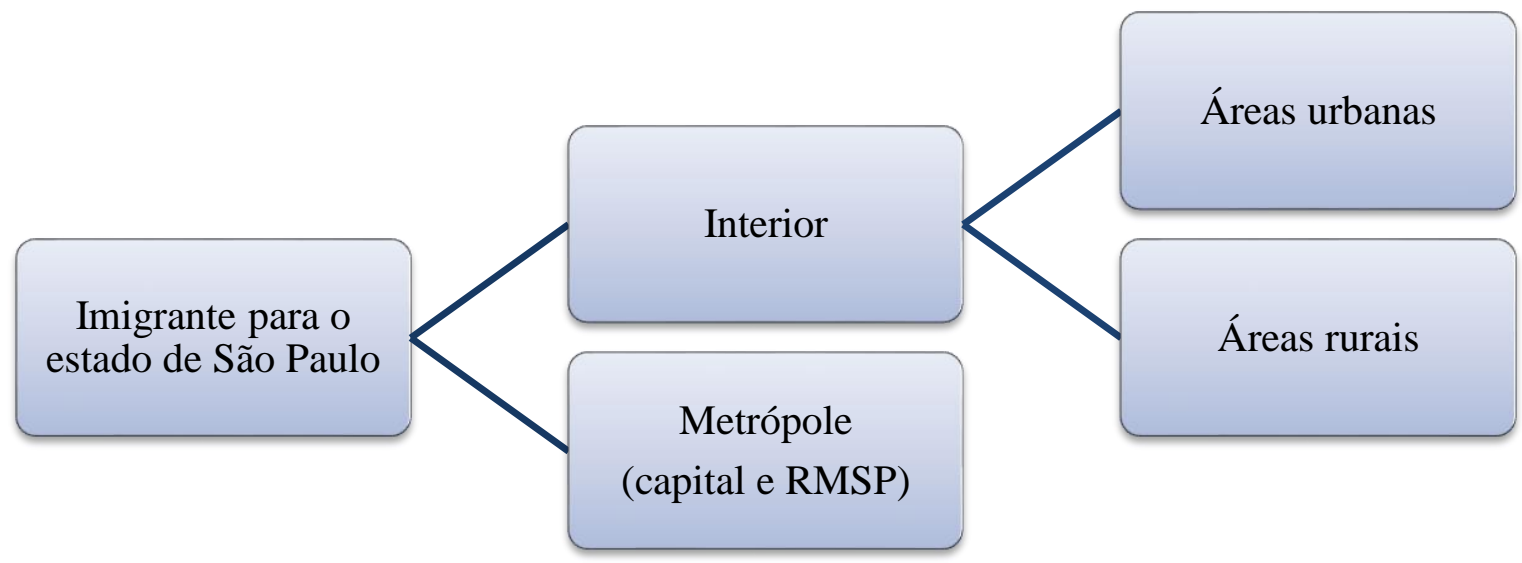

Figura 1 - Categorização dos imigrantes segundo destino no estado de São Paulo

Fonte: Elaboração dos autores

Para que os imigrantes sejam selecionados, é preciso escolher entre usar o quesito "data fixa" ou trabalhar com o quesito "última etapa". No primeiro caso, todos os que migraram há mais de 5 anos não são computados, além de que possíveis migrações nos últimos 5 anos também são perdidas. Por sua vez, o uso do quesito "última etapa" capta apenas o último deslocamento realizado, independente da época no qual este aconteceu. Assim sendo, migrações que ocorreram recentemente e há muito tempo se confundem. 
Como estamos interessados em analisar as migrações de e para São Paulo no século XXI, além de evitarem-se confusões - a respeito das motivações migratórias - que podem ser causadas pelo uso do quesito "última etapa", este trabalho utilizará o quesito "data fixa". Além disto, estaremos trabalhando apenas com a população de 10 anos ou mais, já que é de nosso interesse analisar elementos relacionados a ocupação, rendimento e família.

Feita esta escolha, o próximo passo é definir o que será analisado nos imigrantes. Como o interesse é estudar o perfil socioeconômico e ocupacional dos migrantes de e para São Paulo, a análise é feita levando em conta:

- No caso do estrato socioeconômico, se o imigrante é pobre ou não;

- No caso do perfil ocupacional, em que setor o imigrante se inseriu no destino.

Para a seleção da população pobre, usa-se a linha de pobreza absoluta baseada em cestas básicas de consumo, separando pobres, vulneráveis e não-pobres.

Para a definição da linha de pobreza, parte-se da média dos valores mensais da cesta básica do município de São Paulo em 2010, obtidos pelo Departamento Intersindical de Estatística e Estudos Socioeconômicos (DIEESE). Segundo o decreto-lei 399/1938 (BRASIL, 1938), a cesta básica de alimentos serve para suprir as necessidades alimentícias de um adulto trabalhador. Deste modo, o valor obtido pode ser usado como linha de pobreza extrema - à medida que, se uma pessoa não ganhar o mínimo para satisfazer suas necessidades alimentícias básicas, sua condição de pobreza é crônica. Abaixo, mostra-se a composição desta cesta básica e os valores médios para o município de São Paulo em 2010.

Tabela 1 - Cesta básica de consumo segundo gasto por alimento, município de São Paulo (2010)

\begin{tabular}{lrlrr}
\hline Alimento & Quantidade & \multicolumn{2}{c}{ Valor médio } \\
\hline Carne & $6,0 \mathrm{~kg}$ & $\mathrm{R} \$$ & 83,52 \\
Leite & $15,0 \mathrm{~L}$ & $\mathrm{R} \$$ & 16,43 \\
Feijão & $4,5 \mathrm{~kg}$ & $\mathrm{R} \$$ & 16,75 \\
Arroz & $3,0 \mathrm{~kg}$ & $\mathrm{R} \$$ & 6,13 \\
Farinha & $1,5 \mathrm{~kg}$ & $\mathrm{R} \$$ & 2,75 \\
Batata & $6,0 \mathrm{~kg}$ & $\mathrm{R} \$$ & 14,46 \\
Tomate & $9,0 \mathrm{~kg}$ & $\mathrm{R} \$$ & 25,67 \\
Pão francês & $6,0 \mathrm{~kg}$ & $\mathrm{R} \$$ & 38,13 \\
Café em pó & $0,6 \mathrm{~kg}$ & $\mathrm{R} \$$ & 6,25 \\
Banana & $90 \mathrm{un}$. & $\mathrm{R} \$$ & 16,36 \\
Açúcar & $3,0 \mathrm{~kg}$ & $\mathrm{R} \$$ & 6,23 \\
Óleo & $1,5 \mathrm{~kg}$ & $\mathrm{R} \$$ & 2,33 \\
Manteiga & $0,9 \mathrm{~kg}$ & $\mathrm{R} \$$ & 12,90 \\
\hline Total & & $\mathbf{R} \$$ & $\mathbf{2 4 7 , 8 9}$ \\
\hline
\end{tabular}

Fonte: DIEESE 
De posse deste valor, é preciso calcular o valor do salário mínimo a partir das consideradas despesas fundamentais, para definir o intervalo no qual se encontram os pobres e os vulneráveis à pobreza. Segundo o decreto-lei 399/1938 (BRASIL, 1938), o salário mínimo deve satisfazer as "necessidades normais de alimentação, habitação, vestuário, higiene e transporte". Para isto, é preciso saber o gasto médio com cada um destes itens, o que é obtenível a partir dos dados da POF (Pesquisa de Orçamentos Familiares), a qual foi a campo pela última vez em 2008/2009.

Tabela 2 - Distribuição (\%) da despesa monetária por tipo de despesa e região, 2008/2009

\begin{tabular}{|c|c|c|c|c|c|c|}
\hline Região & $\begin{array}{r}\text { Alimentação } \\
\text { (A) }\end{array}$ & $\begin{array}{r}\text { Habitação } \\
\text { (B) }\end{array}$ & $\begin{array}{r}\text { Vestuário } \\
\text { (C) }\end{array}$ & $\begin{array}{r}\text { Higiene } \\
\text { (D) }\end{array}$ & $\begin{array}{r}\text { Transporte } \\
\text { (E) }\end{array}$ & $(\mathbf{A}) /(\mathbf{E})$ \\
\hline Sudeste & 14,8 & 30,0 & 4,0 & 1,7 & 15,7 & 22,4 \\
\hline São Paulo - UF & 12,2 & 29,2 & 4,0 & 1,7 & 16,4 & 19,2 \\
\hline São Paulo - RM & 14,5 & 30,0 & 3,6 & 1,6 & 16,1 & 22,0 \\
\hline São Paulo & 13,8 & 30,1 & 3,5 & 1,5 & 15,7 & 21,4 \\
\hline
\end{tabular}

Fonte: IBGE, Pesquisa de Orçamentos Familiares 2008/2009 - tabela 1594 do SIDRA

Na tabela acima, se mostra a despesa proporcional para cada item, para o Sudeste, o Estado de São Paulo, a RM de São Paulo e a capital. Para chegar ao valor do limiar de vulnerabilidade à pobreza, precisamos saber qual o valor do salário mínimo individual, dividindo o valor médio da cesta básica de 2010 ( $\mathrm{R} \$ 247,89)$ pela proporção gasta com alimentação. O limiar da vulnerabilidade é, então, definido como:

$$
S M=\frac{C_{S P}}{G_{A}}, \quad G_{A}= \begin{cases}0,220, & \text { se pertencer à RMSP } \\ 0,192, & \text { nos casos contrários }\end{cases}
$$

Com isto, os salários mínimos para a Região Metropolitana de São Paulo e para o interior do estado são, neste trabalho, R \$ 1.126,77 e R \$ 1.291,09, respectivamente. Para definir o limiar de vulnerabilidade, adotamos o valor do salário mínimo para a RMSP, de sorte a ter um padrão para todo o Estado.

Tendo definidas as linhas de pobreza e de vulnerabilidade, conforme se mostra no esquema abaixo, falta informar que a linha de pobreza aqui considerada - como se faz, de modo geral - é o dobro da linha de indigência. Ademais, como se descreveu acima, a cesta básica é para um indivíduo; deste modo, entende-se que as linhas abaixo representam valores per capita. Em outras palavras, cada indivíduo analisado terá sua renda domiciliar per capita comparada às linhas abaixo, sob a hipótese de que os rendimentos obtidos pelos moradores do domicílio são distribuídos equanimemente. A variável do Censo 2010 utilizada para estas análises é a V6531 (rendimento domiciliar per capita em domicílios particulares no dia 31 de Julho de 2010). São excluídas da análise as pessoas que não declararam rendimento no Censo. 


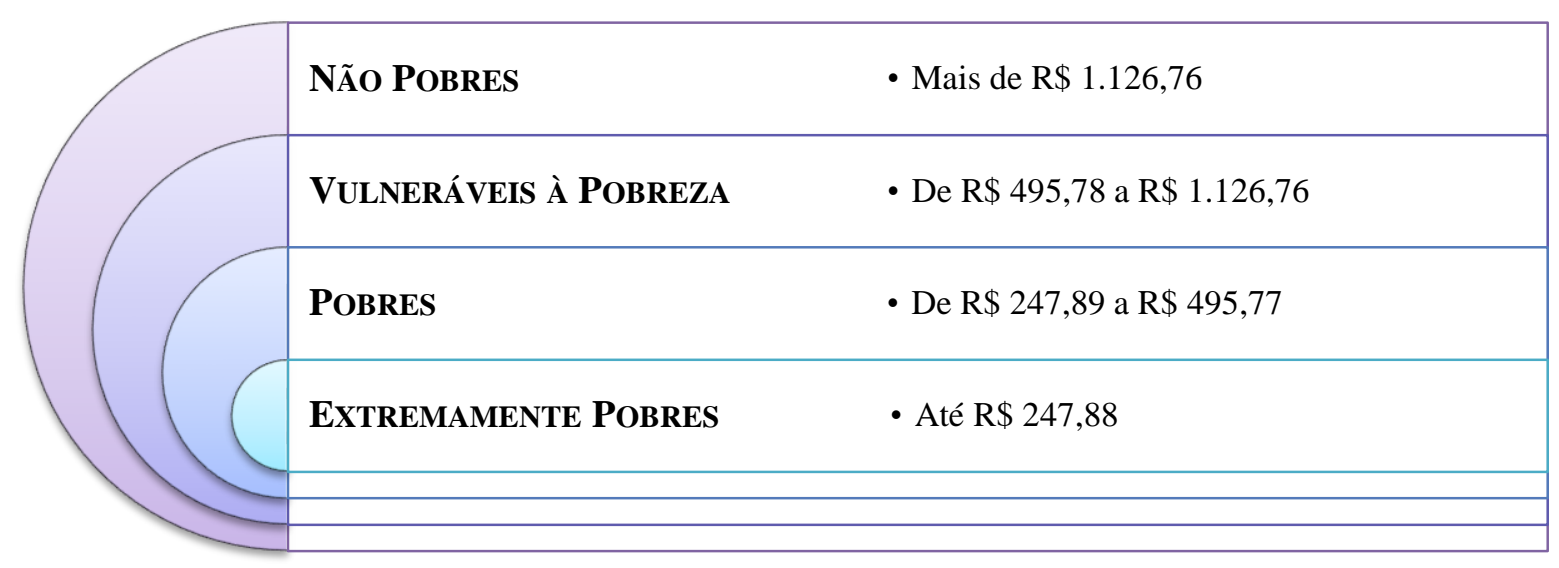

Figura 2 - Categorias de pobreza por renda per capita

Fonte: Elaboração dos autores

A respeito do perfil ocupacional da população imigrante, é possível verificar se, na data de referência, a população era ocupada ou desocupada. Ademais, no caso de ser ocupada, se pode analisar a posição na ocupação. Por meio destas variáveis é possível saber o perfil ocupacional dos imigrantes para o estado de São Paulo por estrato socioeconômico (definido conforme a Figura 2). Estas análises podem ser feitas utilizando-se as seguintes variáveis:

- V6930: posição na ocupação e categoria do emprego no trabalho principal;

- V6910: condição de ocupação na semana de referência.

Complementarmente às variáveis de pobreza e ocupação, são utilizadas algumas caraterísticas sociodemográficas da população para se desenhar um perfil mais acurado da imigração entre 2005 e 2010. Estas variáveis (e seus respectivos códigos) são: 1) sexo (V0601); 2) raça/cor (V0606); 3) nível de instrução (V6400); e 4) estado civil (V0640).

\section{RESULTADOS}

A seguir, são apresentados os resultados das análises, descrevendo - primeiramente de forma separada - a Região Metropolitana de São Paulo e o interior (dividido em urbano e rural), para depois fazer alguns breves comentários comparativos, especialmente sobre o que diz respeito às questões de ocupação da população imigrante no período 2005-2010. Os resultados apresentados abarcam uma análise geral da migração por região de origem (macrorregião ou exterior) e características sociodemográficas.

\section{Região Metropolitana de São Paulo (RMSP)}

Analisando o perfil dos imigrantes rumo à RMSP, a grande maioria é originária do Sudeste e do Nordeste. Isto nos leva a considerar que, no caso do Sudeste, há um fluxo 
constante no sentido interior-capital, em busca de mais oportunidades - por exemplo, por conta das universidades ou das oportunidades de emprego -, enquanto o fluxo saindo do Nordeste tem a ver com a procura adicional por melhores condições de vida. Estes resultados relembram duas das leis de migração de Ravenstein (1980), segundo o qual a grande maioria dos migrantes faz pequenos deslocamentos e os que migram para mais longas distâncias o fazem rumo a centros comerciais/industriais (como é o caso da RMSP).

A maior parte dos imigrantes é vulnerável à pobreza (cerca de $1 \frac{1}{3}$ do total), embora sua distribuição segundo região de origem não seja tão uniforme. Esta afirmação tem respaldo à medida que, quando analisamos a imigração por região e estrato socioeconômico, o maior volume de imigrantes não pobres é do Sudeste, enquanto aumenta significativamente a participação de nordestinos à medida que analisamos estratos inferiores. Outro resultado interessante é o aumento - conforme subimos o estrato socioeconômico - da participação dos imigrantes internacionais na RMSP, passando de cerca de 3\% entre pobres e muito pobres para mais de $6,5 \%$ entre os não pobres.

Gráfico 1 - Proporção de imigrantes segundo origem e estrato socioeconômico, Região Metropolitana de São Paulo (2010)

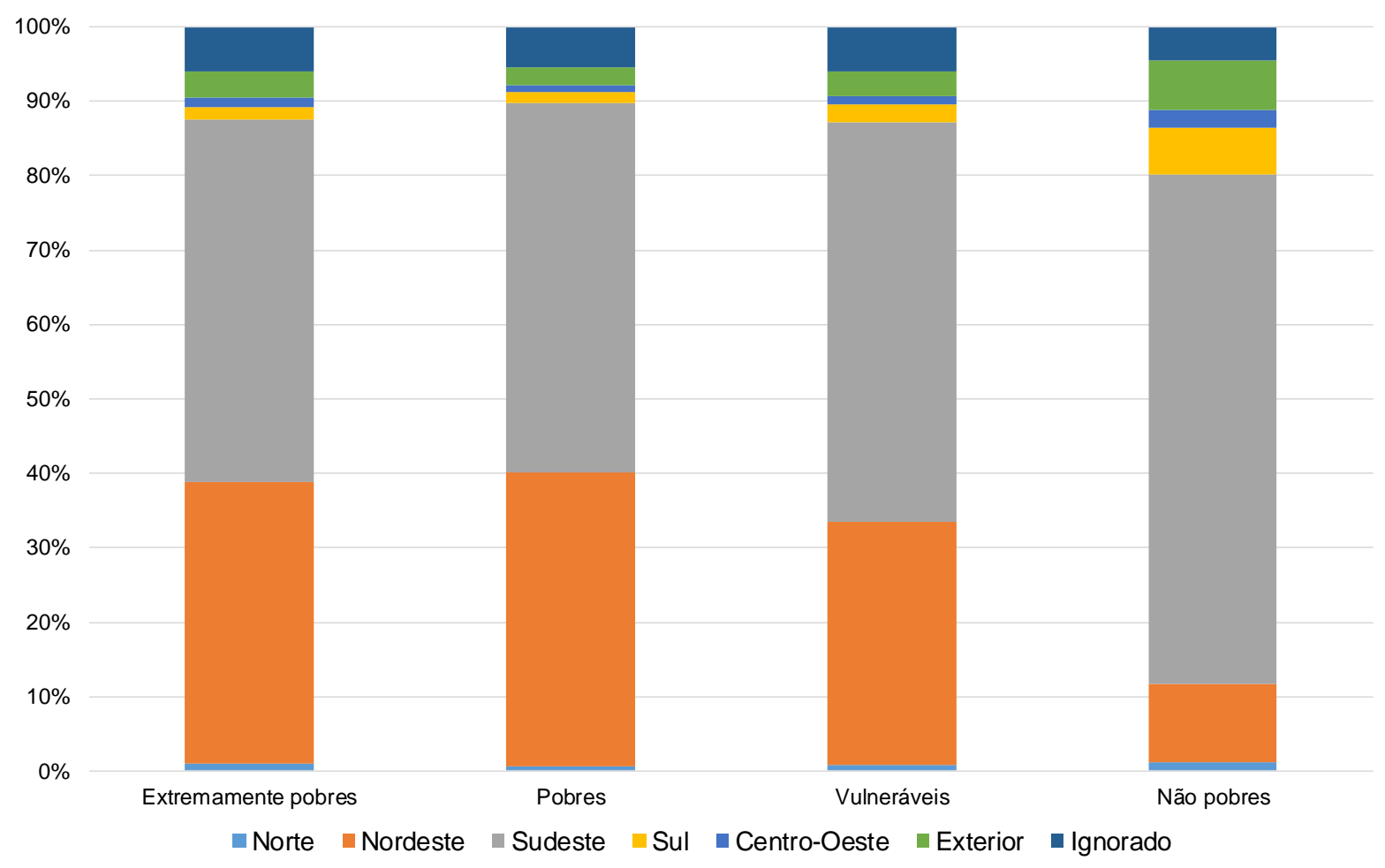

Fonte: IBGE, Censo Demográfico de 2010. Tabulações especiais NEPO/UNICAMP

Fazendo a análise por sexo, segundo local de origem, percebe-se a necessidade de um estudo mais cauteloso dos resultados. Primeiramente, quando se analisam os imigrantes 
internacionais, se percebe que - independentemente do estrato socioeconômico atual - a maioria é do sexo masculino, reafirmando uma das leis da migração de Ravenstein (1980), segundo a qual a migração é proeminentemente feminina, mas as de mais longa distância são realizadas pelos homens, em primeiro lugar.

Desagregando por raça/cor e estrato socioeconômico, se percebe que, entre os muito pobres, a distribuição é bastante homogênea, exceção feita aos originários do Sul e do Exterior (de onde $2 / 3$ dos imigrantes são brancos) e do Nordeste (onde a tendência é inversa). Quando se analisam os pobres e os vulneráveis, há uma tendência à migração ser dos nãobrancos (aqui entendidos como pretos, pardos e indígenas), sempre com exceção do Sul (de onde os fluxos de emigração são majoritariamente de brancos, não importando o nível de renda). Todavia, quando se analisa o estrato socioeconômico "não pobre", percebe-se que a imigração rumo à Região Metropolitana de São Paulo se torna uma característica da população branca: com exceção da região Nordeste, todas as outras origens - neste estrato socioeconômico - têm mais de $75 \%$ de seus migrantes sendo brancos.

Gráfico 2 - Proporção de imigrantes segundo origem, estrato socioeconômico, raça/cor e sexo, Região Metropolitana de São Paulo (2010)

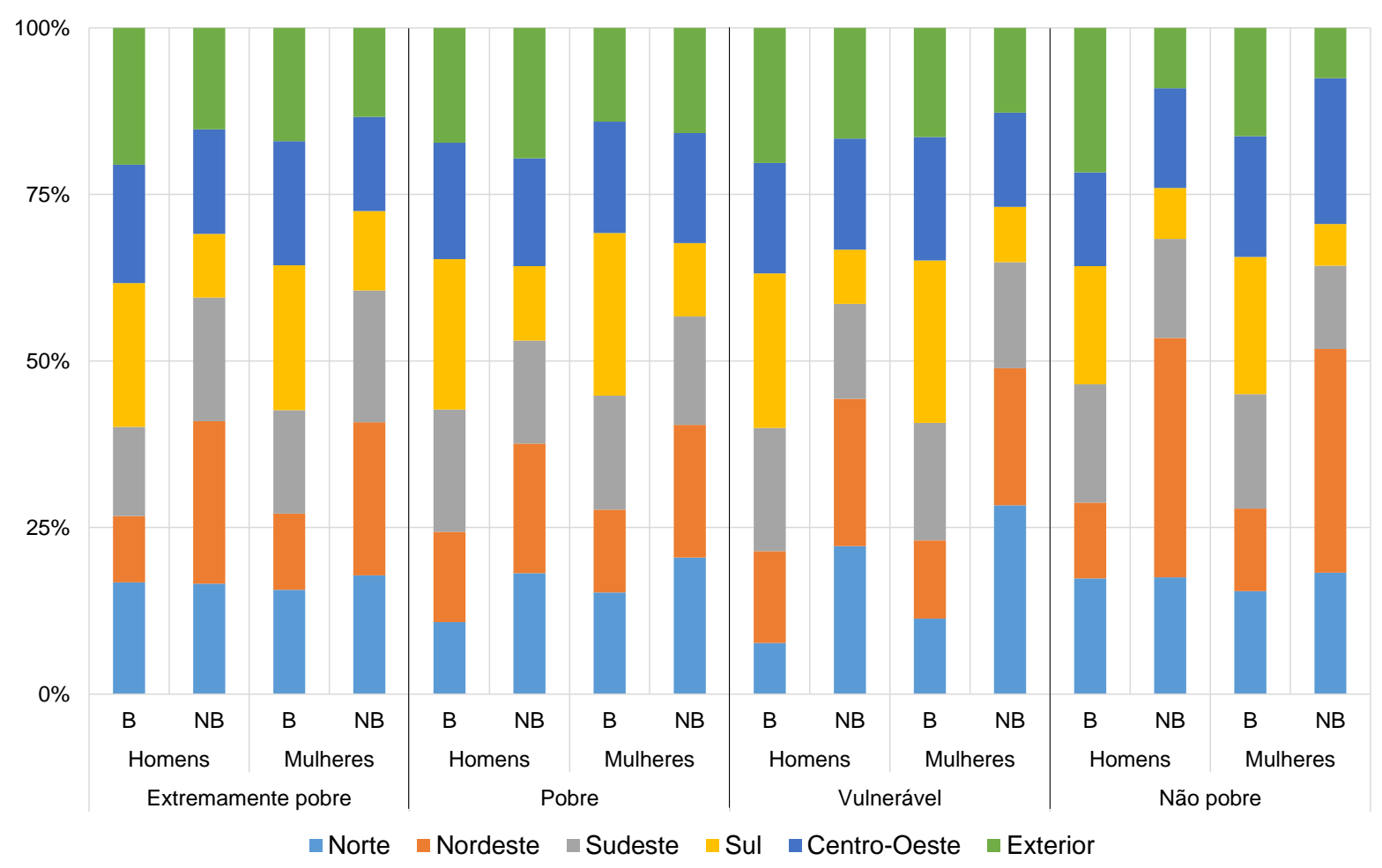

Fonte: IBGE, Censo Demográfico de 2010. Tabulações especiais NEPO/UNICAMP

Nota: "B" indica a soma de brancos e amarelos e "NB" indica a soma de pretos, pardos e indígenas 
Em termos de fluxos com base no estado civil e no sexo, percebe-se que, de maneira geral, o deslocamento é majoritariamente de solteiros ou casados, independente da região de origem. As migrações de pessoas casadas são mais intensas com o aumento do estrato socioeconômico - sendo mais clara a diferença entre não pobres e os outros estratos. A migração de viúvos é residual, remetendo ao fato de pessoas com este estado civil tendem a ser mais velhas e, portanto, a migrarem menos. As mulheres separadas ou divorciadas tendem a migrar mais para a RMSP do que os homens, sobretudo nos estratos inferiores de renda.

Tabela 3 - Distribuição (\%) das imigrações segundo estrato socioeconômico, região de origem, estado civil e sexo, Região Metropolitana de São Paulo (2010)

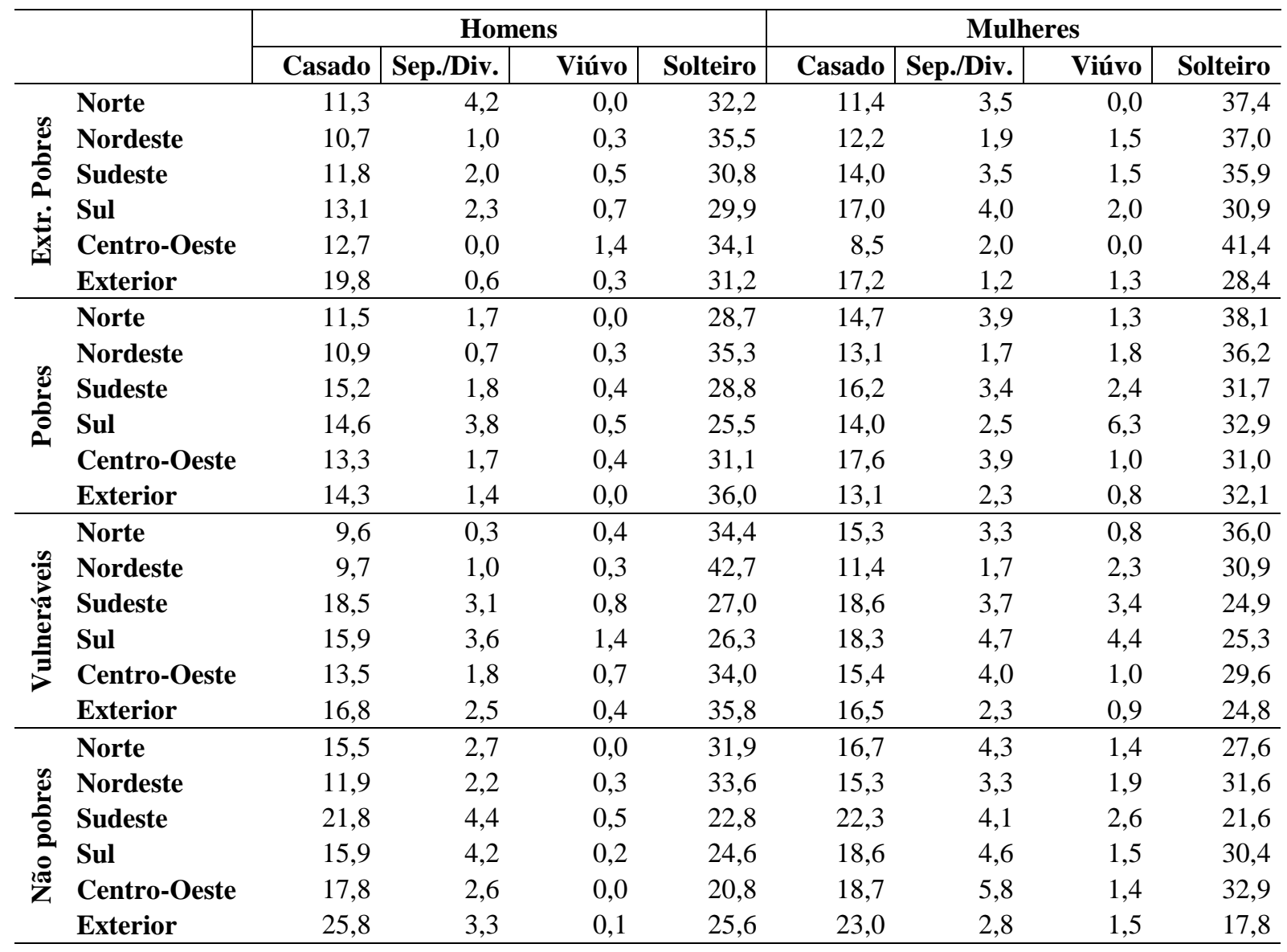

Fonte: IBGE, Censo Demográfico de 2010. Tabulações especiais NEPO/UNICAMP

Finalmente, quando se analisa a distribuição dos imigrantes segundo nível de escolaridade e sexo, percebe-se que a maior parte da migração de pessoas extremamente pobres e pobres é de imigrantes com baixa escolaridade (aqui definida como sem ensino médio completo). Nestes fluxos, as maiores discrepâncias são (entre os mais pobres) nos estados das regiões Norte e Nordeste - onde 4 em cada 5 imigrantes para a RMSP têm baixa escolaridade - e, entre os pobres, no Nordeste e no Sul. Por sua vez, quando o migrante está 
no estrato socioeconômico "não pobre", este tende a ser mais escolarizado, especialmente os oriundos do Sul e Sudeste e do exterior.

Gráfico 3 - Proporção de imigrantes segundo origem, estrato socioeconômico, nível de escolaridade e sexo, Região Metropolitana de São Paulo (2010)

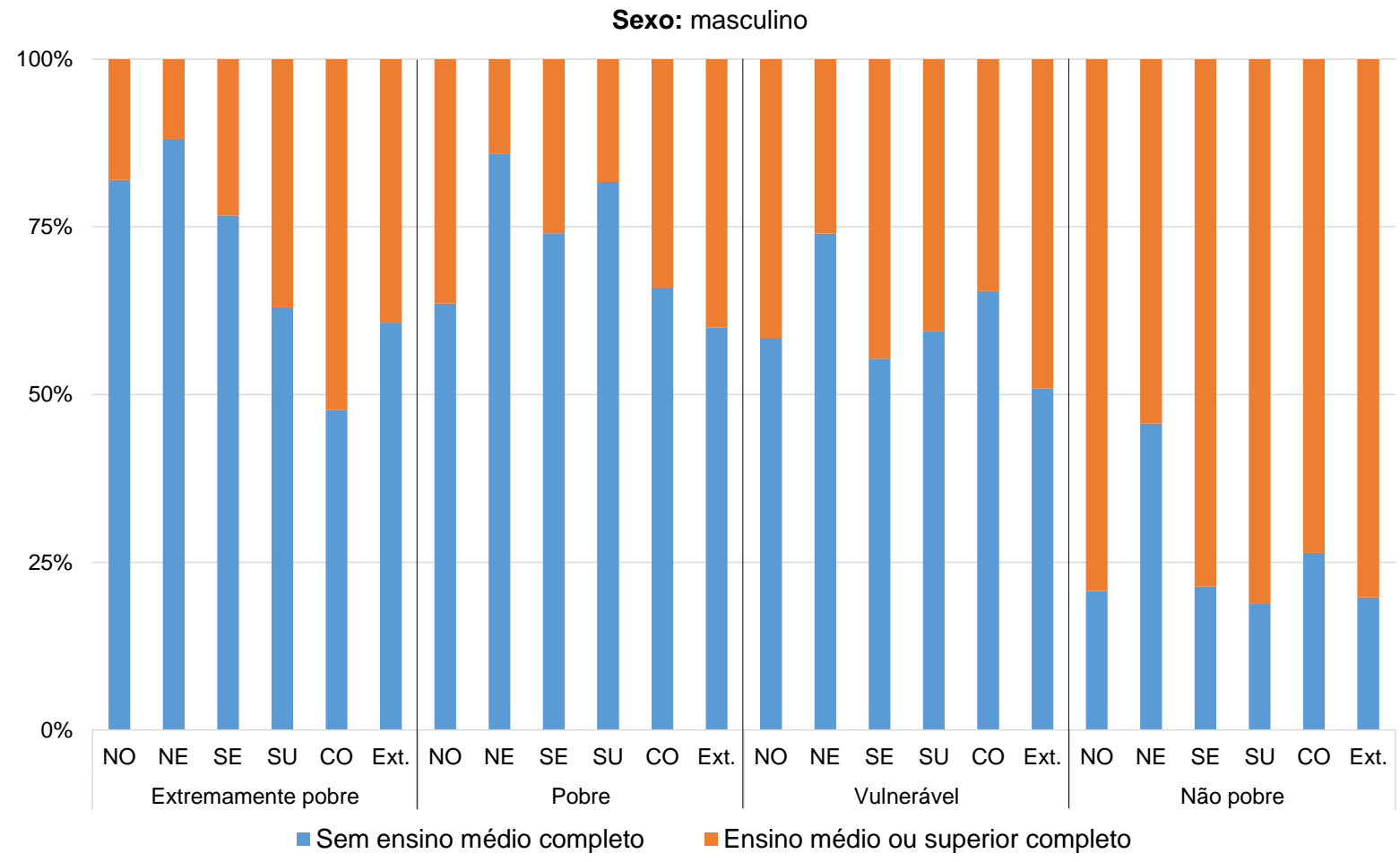

Sexo: feminino

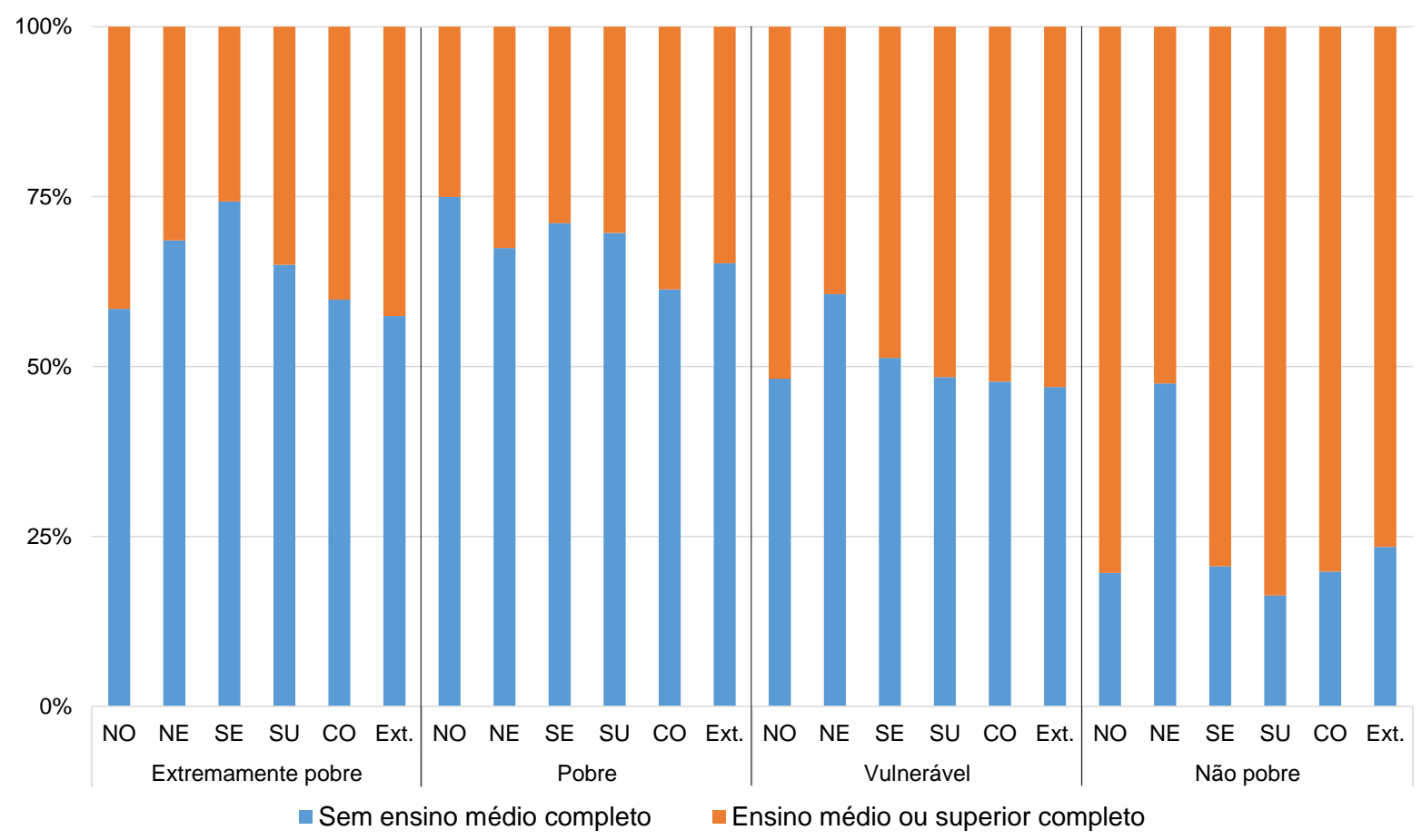

Fonte: IBGE, Censo Demográfico de 2010. Tabulações especiais NEPO/UNICAMP 


\section{Interior paulista - urbano e rural}

A migração para o interior paulista - definido, neste trabalho, como sendo toda a área que não compreende a RMSP - é, diferentemente do que se verificou para os fluxos rumo à RMSP, um fenômeno destacadamente da população do Sudeste em si. A grande maioria dos imigrantes que se mudam para o interior do estado de São Paulo são do próprio estado, o que caracteriza a mobilidade intra-estadual na década, sendo que esta proporção fica ainda mais clara ao analisar-se apenas as áreas rurais. Por sua vez, se - na RMSP - o estrato de renda determinava a proporção de imigrantes oriundos de outras regiões que não o Sudeste, especialmente para as áreas rurais se nota que a renda não faz a menor diferença. Já a migração para o interior urbano leva em conta algum elemento de cunho socioeconômico, possivelmente associado ao fato de os que mais ganham procurarem melhores condições de vida fora da grande metrópole paulista.

Tabela 4 - Distribuição (\%) das imigrações segundo estrato socioeconômico, região de origem e região de destino, estado de São Paulo (2010)

\begin{tabular}{llr|r|r|r|r|r|r}
\hline Estrato & Destino & Norte & Nordeste & Sudeste & Sul & C. Oeste & Exterior & Não sabe \\
\hline \multirow{2}{*}{$\begin{array}{l}\text { Extremamente } \\
\text { pobres }\end{array}$} & RMSP & 0,9 & 37,8 & 48,7 & 1,8 & 1,2 & 3,6 & 6,0 \\
& Int. urbano & 0,7 & 16,2 & 64,3 & 3,4 & 2,3 & 1,9 & 11,2 \\
& Int. rural & 0,3 & 6,5 & 82,9 & 3,9 & 2,0 & 0,6 & 3,8 \\
\hline \multirow{3}{*}{ Pobres } & RMSP & 0,6 & 39,6 & 49,6 & 1,4 & 1,0 & 2,4 & 5,4 \\
& Int. urbano & 1,0 & 17,8 & 63,9 & 3,8 & 2,4 & 1,2 & 9,9 \\
& Int. rural & 0,3 & 6,5 & 82,0 & 5,2 & 2,5 & 0,2 & 3,2 \\
\hline \multirow{2}{*}{ Vulneráveis } & RMSP & 0,7 & 32,7 & 53,7 & 2,4 & 1,1 & 3,4 & 5,9 \\
& Int. urbano & 0,7 & 13,6 & 67,9 & 4,2 & 2,3 & 1,5 & 9,8 \\
& Int. rural & 0,9 & 6,4 & 82,4 & 4,7 & 2,3 & 0,7 & 2,6 \\
\hline \multirow{3}{*}{ Não pobreary } & RMSP & 1,3 & 10,5 & 68,5 & 6,2 & 2,5 & 6,6 & 4,6 \\
& Int. urbano & 0,8 & 4,1 & 75,7 & 4,9 & 2,6 & 2,5 & 9,4 \\
& Int. rural & 0,4 & 4,6 & 83,6 & 3,6 & 3,3 & 1,5 & 3,0 \\
\hline
\end{tabular}

Fonte: IBGE, Censo Demográfico de 2010. Tabulações especiais NEPO/UNICAMP

Em suma, se nota que a imigração para o estado de São Paulo é principalmente intraestadual, quando se leva em conta o interior (sobretudo as áreas rurais) do estado, enquanto tem participação significativa (entre $1 / 3$ e $1 / 2$ ) de outros estados, e até do exterior, quando se analisam em separado as migrações rumo à Região Metropolitana de São Paulo. As diferenças entre as áreas urbanas e rurais do interior paulista - tênues, à primeira vista - ficam mais evidentes quando se desagrega a proporção de imigrantes a partir do nível de escolaridade.

Como se nota no gráfico abaixo, os imigrantes para as áreas urbanas - tanto para os homens, como no caso das mulheres - são mais escolarizados. Nota-se, todavia, que a heterogeneidade é maior entre os homens do que entre as mulheres - ou seja, os homens que 
migram para as áreas rurais do interior paulista são, em média, muito menos escolarizados que as mulheres que migram para as mesmas áreas.

Gráfico 4 - Proporção de imigrantes por nível de escolaridade, sexo, estrato socioeconômico, região de origem e área de destino no interior paulista, estado de São Paulo (2010)

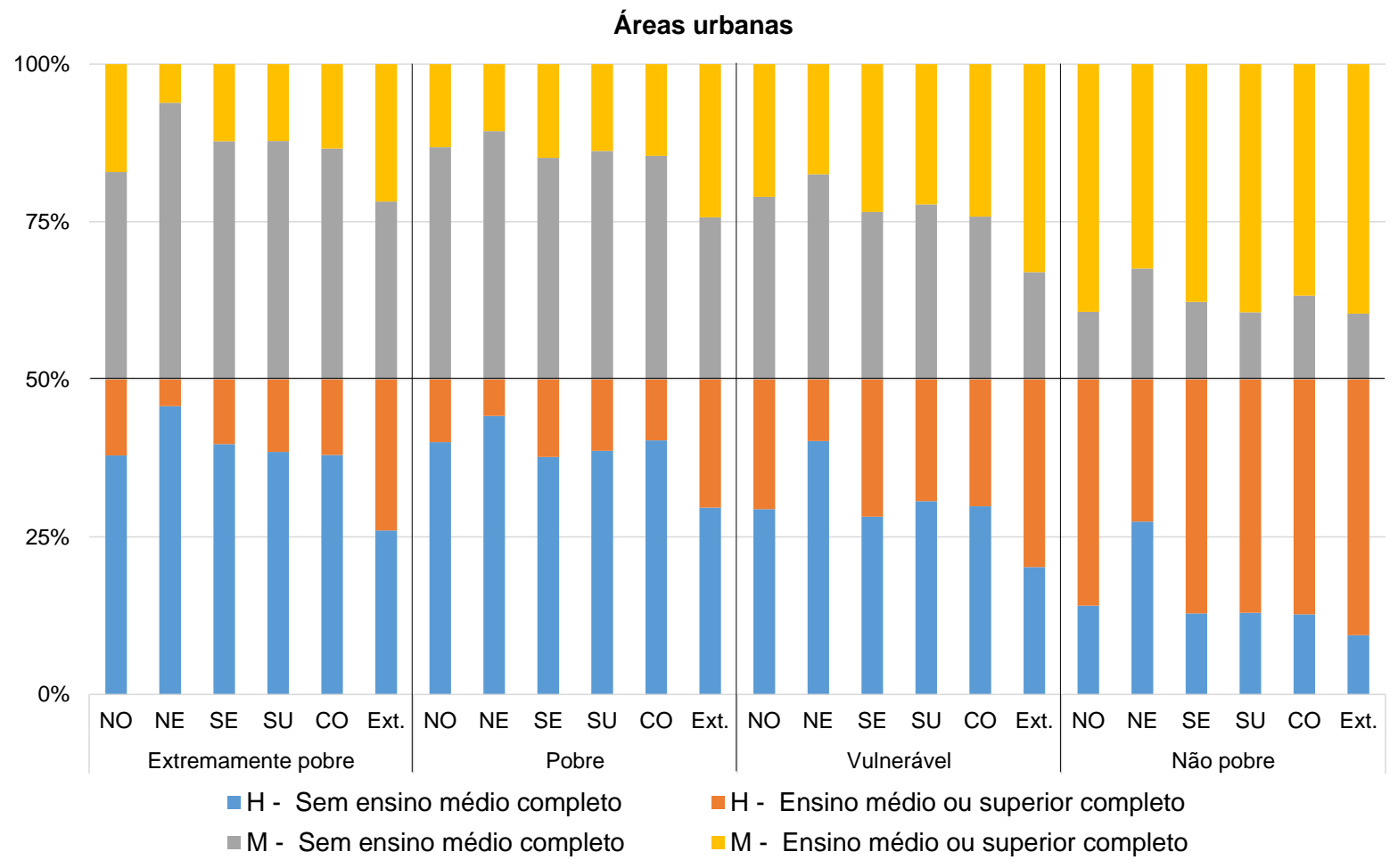

Áreas rurais

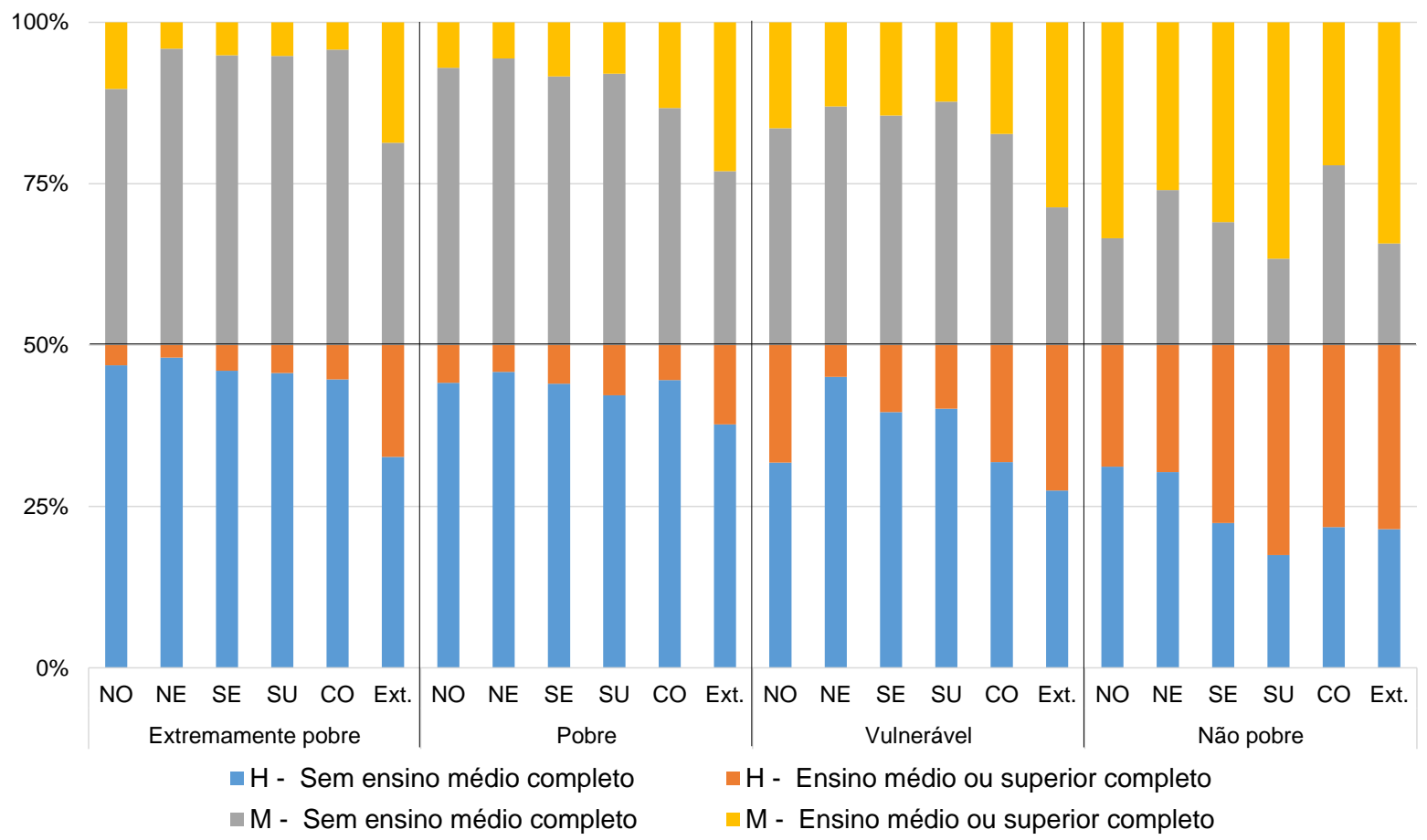

Fonte: IBGE, Censo Demográfico de 2010. Tabulações especiais NEPO/UNICAMP 
Desagregando a migração pelo quesito raça/cor, nota-se que a imigração, oriunda de Norte e Nordeste, para as áreas urbanas do interior paulista é predominantemente de pretos e pardos, independentemente do estrato socioeconômico. Nas áreas rurais, a imigração desta população é majoritária para todas as regiões do país dentre os extremamente pobres; já para os outros estratos, não há um padrão homogêneo. As imigrações internacionais para o interior paulista são preponderantemente de brancos e amarelos, havendo pouca ou nenhuma representatividade de pretos e pardos.

Gráfico 5 - Distribuição dos imigrantes por raça/cor, estrato socioeconômico, região de origem e área de destino no interior paulista, estado de São Paulo (2010)

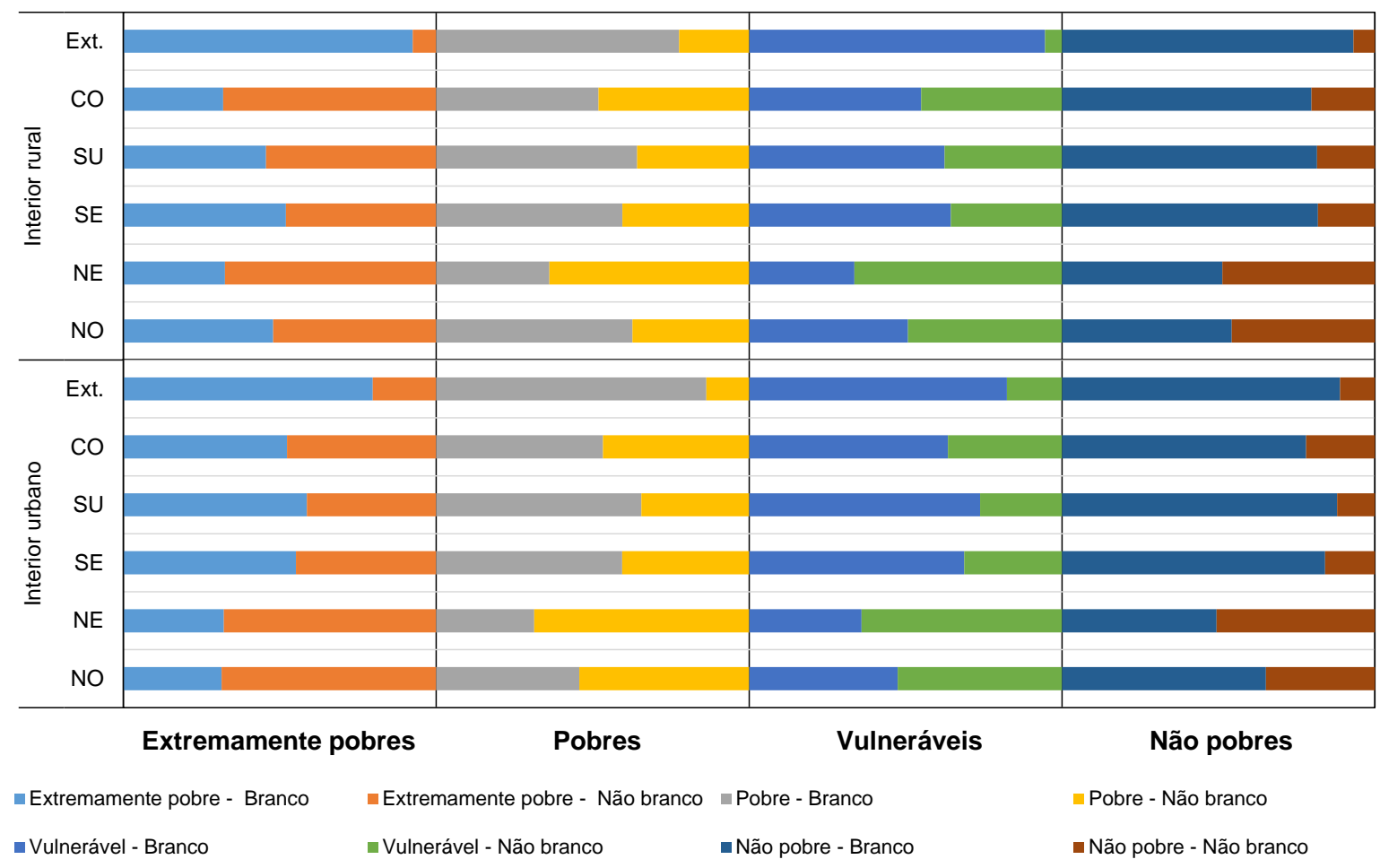

Fonte: IBGE, Censo Demográfico de 2010. Tabulações especiais NEPO/UNICAMP

As tendências, relativas ao estado civil, para o interior do estado são similares àquelas encontradas para a RMSP como um todo. O que chama bastante atenção, todavia, é o fato de haver uma substancialmente maior participação de separados e divorciados nas migrações para o interior do que para a RMSP, especialmente nos estratos superiores de renda. Isto pode indicar, possivelmente - dado que a migração para o interior paulista é preponderantemente de pessoas que, anteriormente, já moravam no Sudeste -, para um fluxo ocorrendo em um estágio avançado do ciclo de vida familiar, quando um núcleo familiar se rompe. 
Gráfico 6 - Proporção de divorciados segundo estrato socioeconômico, região de origem e área de destino, estado de São Paulo (2010)

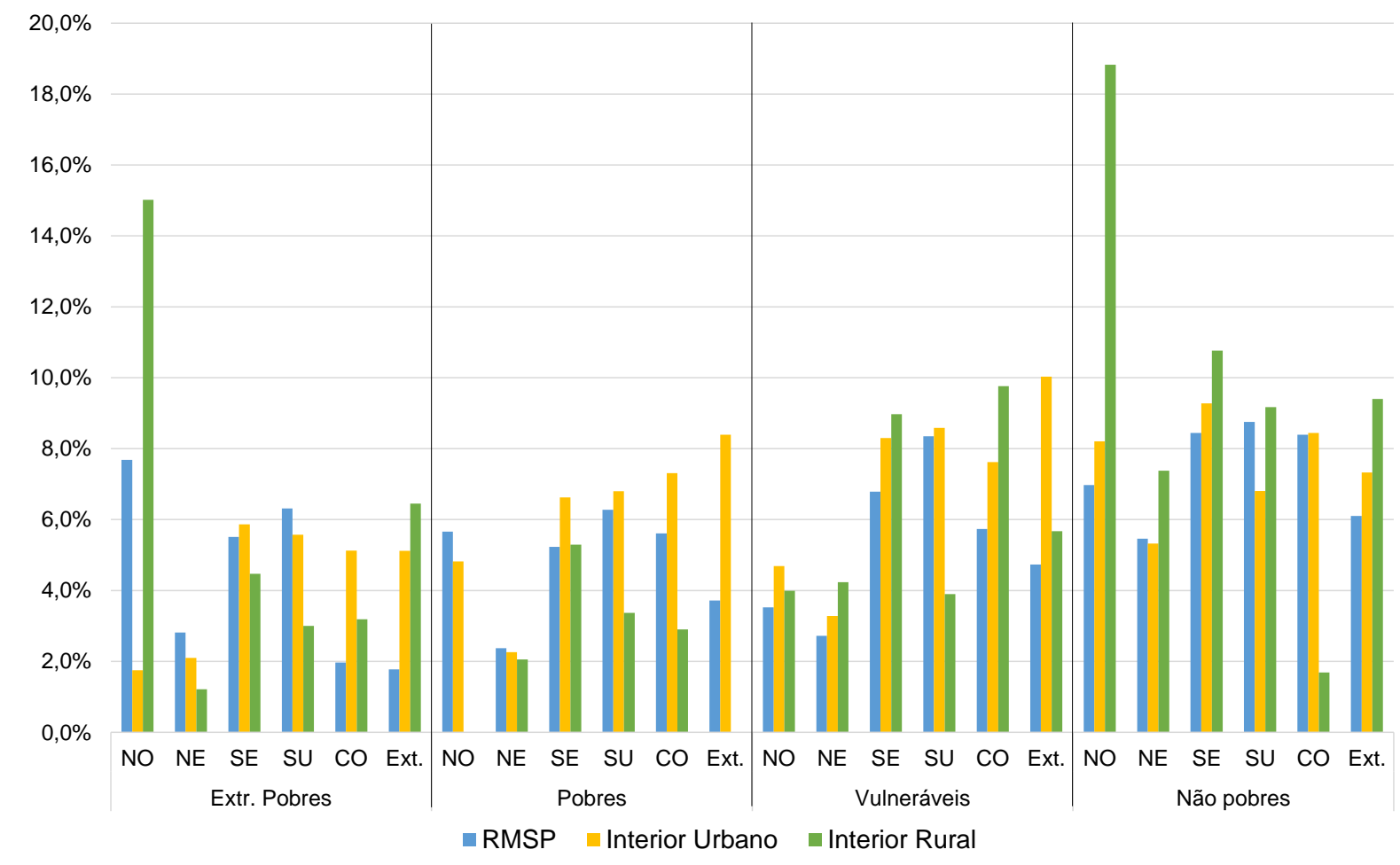

Fonte: IBGE, Censo Demográfico de 2010. Tabulações especiais NEPO/UNICAMP

\section{Comparações em termos de ocupação}

Finalmente, estabelecemos algumas relações a respeito da situação de ocupação dos migrantes que foram morar no estado de São Paulo. Nota-se, de forma generalizada, que a proporção de imigrantes ocupados é maior dentre aqueles que vão morar na RMSP, seguidos dos que se deslocam para o interior urbano. Como era de se esperar, a proporção de população imigrante ocupada é maior quanto maior o estrato socioeconômico de renda.

Desagregando os ocupados por situação na ocupação, percebe-se que, na RMSP, a maioria dos ocupados trabalha (geralmente com carteira assinada, mesmo que ainda existe uma proporção entre $1 / 2$ e $1 / 4$ que ainda trabalha sem registro em carteira). Ao elevar-se o estrato de renda, aumenta a proporção de ocupados em conta própria, sendo que a grande maioria dos ocupados neste ramo são imigrantes internacionais.

Analisando os migrantes para o interior paulista urbano, a proporção de ocupados com carteira de trabalho assinada é ainda mais preponderante em relação à mesma proporção na RMSP. Consequentemente, há proporcionalmente menos ocupados por conta própria dentre os imigrantes que foram residir no interior urbano. Nas áreas rurais, a proporção de ocupados sem carteira assinada é maior dentre os extremamente pobres - tendência inversa à encontrada 
na RMSP e no interior urbano -, enquanto a proporção de pessoas que trabalham com carteira assinada é maior nos outros estratos. Novamente, assim como na RMSP, a proporção de imigrantes internacionais ocupados por conta própria é majoritária, sendo opção de 1 em cada 3 ocupados que estão nos estratos "vulnerável" e "não pobre".

Gráfico 7 - Proporção de ocupados segundo estrato socioeconômico, região de origem e área de destino, estado de São Paulo (2010)

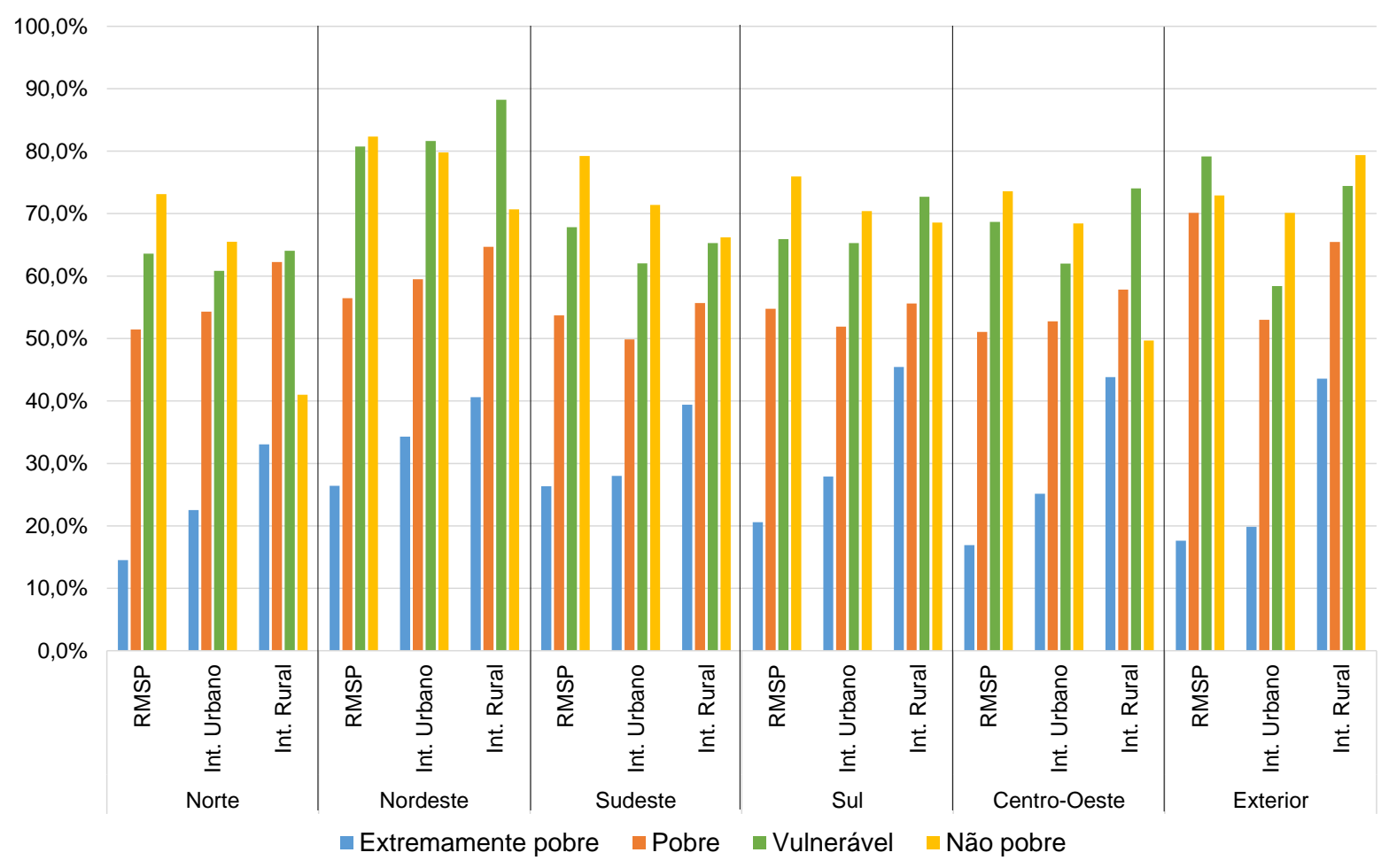

Fonte: IBGE, Censo Demográfico de 2010. Tabulações especiais NEPO/UNICAMP

Percebe-se, assim, que há associação entre ocupados com carteira assinada e as regiões mais urbanizadas e industrializadas do estado de São Paulo. A preponderância desta situação de ocupação na RMSP espelha o fato de esta região metropolitana ser a que mais ocupa e se expande em termos econômicos - embora o interior paulista tenha se tornado alvo de maiores fluxos migratórios nos últimos anos. Analisando, finalmente, a estruturação da ocupação segundo região de origem, nota-se que as maiores proporções de ocupados são de pessoas que são originárias do Nordeste. Esta tendência se reflete em qualquer estrato socioeconômico e em toda área de destino - ou seja, os imigrantes nordestinos têm a maior proporção de sua população, em relação às outras regiões, ocupada com carteira assinada. 


\section{CONSIDERAÇÕES FINAIS}

Neste trabalho, analisou-se o perfil da imigração para o estado de São Paulo na primeira década do século XXI. A análise levou em conta o perfil socioeconômico, algumas variáveis sociodemográficas e a estrutura de ocupação da população. A hipótese principal do trabalho era a existência de algum grau de homogeneidade entre os perfis dos imigrantes para a RMPS e para o interior paulista (tanto urbano, quanto rural). Objetivou-se, com este estudo, verificar a existência de diferenças consistentes entre o interior e a metrópole paulistas, com o propósito de discutir se a diferenciação - para o estado de São Paulo - entre metrópole e interior é válida.

Constatou-se, com os resultados apresentados, que há algumas diferenças sim, entre o interior e a metrópole, especificamente no que diz respeito ao perfil ocupacional da população imigrante e à composição dos fluxos imigratórios. Alguma diferença menor foi encontrada em termos de estado civil da população imigrante - havendo mais divorciados e separados indo morar no interior do estado. Entretanto, não se notaram - pelo menos entre o interior paulista urbano e a RMSP - diferenças tão gritantes em termos do perfil da migração. O que mantém em pé a separação entre interior e metrópole é a composição dos fluxos migratórios stricto sensu, já que as imigrações para o interior são preponderantemente de paulistas.

Conclui-se, então, que, embora as diferenças entre o interior e a metrópole não sejam tão significativas - aparecendo de forma mais evidente entre o interior urbano e o rural -, o fato de o fluxo para o interior ser majoritariamente de paulistas faz com a separação seja extremamente necessária. Isto se justifica pelo fato de as características socioeconômicas dos paulistas serem bastante diferentes das encontradas no restante do país, especialmente das observadas no Norte e Nordeste do Brasil.

O interior do estado de São Paulo é relativamente heterogêneo, de sorte que alguns resultados possam ter sido afetados pela presença de regiões metropolitanas importantes, como a de Campinas (RMC) e a da Baixada Santista (RMBS). A diferenciação entre metrópoles e interior do estado é necessária, mas não pode se limitar à separação entre RMSP e o resto do estado. Os resultados para o interior de São Paulo - especialmente das áreas urbanas - podem ter sofrido de algum efeito de composição, fruto da coexistência, nesta região, de áreas muito desenvolvidas economicamente (como as regiões metropolitanas) com outras áreas que estão em processo de expansão urbana. 


\section{REFERÊNCIAS BIBLIOGRÁFICAS}

BAENINGER, R. Região, Metrópole e Interior: espaços ganhadores e espaços perdedores nas migrações recentes no Brasil - 1980/1996. Tese (Doutorado em Demografia) - Instituto de Filosofia e Ciências Humanas, Universidade Estadual de Campinas. Campinas, 1999.

. Fases e faces da migração em São Paulo. Campinas: Núcleo de Estudos de População NEPO/UNICAMP, 2012.

BECK, U. Risk Society: Towards a new modernity. Sage Publications, London, 1992.

BRASIL. Decreto-Lei no 399, de 30 de abril de 1938. Aprova o regulamento para execução da lei n. 185, de 14 de janeiro de 1936, que institue as Comissões de Salário Mínimo. Diário Oficial da União, Poder Executivo, Rio de Janeiro, 30 abr. 1938.

BRITO, F. População, espaço e economia numa perspectiva histórica: o caso brasileiro. Tese (Doutorado em Economia) - Faculdade de Ciências Econômicas, Universidade Federal de Minas Gerais. Belo Horizonte, 1997.

CANO, W. (Coord.). A Interiorização do Desenvolvimento Econômico no Estado de São Paulo (1920-1980). São Paulo: Fundação SEADE, volumes 1 a 3 (Coleção Economia Paulista), 1998.

CUNHA, J. M. P. (Coord.). Mobilidade e redistribuição espacial da população no Estado de São

Paulo: características recentes, padrões e impactos no processo de urbanização. Campinas: NEPO/UNICAMP, 1999. 273p. (Relatório Final)

GIDDENS, A. As Conseqüências da Modernidade. São Paulo: Editora UNESP, 1991.

MARTINE, G.; CAMARGO, L. Crescimento e distribuição da população brasileira: tendências recentes. Revista Brasileira de Estudos de População. Campinas, Associação Brasileira de Estudos de População, v. 1, n. 2, 1984. pp. 99-143.

MARTINE, G. Migração e Metropolização. Revista São Paulo em Perspectiva. São Paulo, Fundação SEADE, 1987.

MATOS, R. E. S. Dinâmica migratória e desconcentração da população na macrorregião de Belo Horizonte. Tese (Doutorado em Demografia) - Centro de Desenvolvimento e Planejamento Regional, Universidade Federal de Minas Gerais. Belo Horizonte, 1995.

OJIMA, R. Urbanização e Meio Ambiente: os arranjos institucionais e os desafios para a gestão metropolitana. In: Anais do I Encontro Transdiciplinar sobre Espaço e População. Campinas: Associação Brasileira de Estudos de População, 2003. v. 1

PACHECO, C. A. e PATARRA, N. L. Movimentos Migratórios nos Anos 80: novos padrões? In: Anais do Encontro Nacional sobre Migração, Curitiba, 1997.

RAVENSTEIN, E. G. As leis das migrações. In: MOURA, H. (Org.). Migração interna: textos selecionados. Fortaleza: Banco do Nordeste do Brasil S.A, 1980. pp. 25-88. [Original de 1885].

SINGER, P. Migrações internas: considerações teóricas sobre seu estudo. In: SINGER, P. Economia política da urbanização. São Paulo: Brasiliense, 1973. 